Entry

\title{
Air Quality during Covid-19 Lockdown
}

\author{
Gabriele Donzelli ${ }^{1,2, *(\mathbb{D})}$, Lorenzo Cioni ${ }^{3} \mathbb{D}$, Mariagrazia Cancellieri $^{4}$, Agustin Llopis-Morales ${ }^{1}$ \\ and María Morales-Suárez-Varela ${ }^{1,5}$ (D)
}

1 Department of Preventive Medicine and Public Health, Food Sciences, Toxicology, and Legal Medicine, School of Pharmacy, University of Valencia, Avenida Vicente Andres Estellés s/n, Burjassot, 46100 Valencia, Spain; allomo3@alumni.uv.es

2 Department of Health Sciences, University of Florence, Viale GB Morgagni 48, 50134 Florence, Italy

3 Scuola Normale Superiore, Piazza dei Cavalieri 7, 56126 Pisa, Italy; lorenzo.cioni@sns.it

4 Hygiene and Public Health Unit, Department of Public Health, AUSL Imola, Viale Giovanni Amendola 2, 40026 Bologna, Italy; m.cancellieri@ausl.imola.bo.it (M.C.); Maria.M.Morales@uv.es (M.M.-S.-V.)

5 Biomedical Research Consortium in Epidemiology and Public Health Network (CIBERESP), Avenida Monforte de Lemos, 3-5. Pabellón 11. Planta 0, 28029 Madrid, Spain

* Correspondence: gadon@alumni.uv.es

Citation: Donzelli, G.; Cioni, L.; Cancellieri, M.; Llopis-Morales, A.; Morales-Suárez-Varela, M. Air Quality during Covid-19 Lockdown. Encyclopedia 2021, 1, 519-526. https:/ / doi.org/10.3390/encyclopedia1030043

Academic Editor: Stephen Bustin

Received: 23 June 2021

Accepted: 28 June 2021

Published: 1 July 2021

Publisher's Note: MDPI stays neutral with regard to jurisdictional claims in published maps and institutional affiliations.

Copyright: (c) 2021 by the authors. Licensee MDPI, Basel, Switzerland. This article is an open access article distributed under the terms and conditions of the Creative Commons Attribution (CC BY) license (https:// creativecommons.org/licenses/by/ $4.0 /)$.
Definition: Air pollution exposure is one of the greatest risks to health worldwide. It is estimated to be responsible for about 4.2 million deaths around the world every year owing to many serious diseases such as heart disease, stroke, acute and chronic respiratory diseases, and lung cancer. The WHO guideline limits are exceeded in several areas around the world, and it is estimated that about $90 \%$ of the world's population is exposed to high air pollution levels, especially in low- and middleincome countries. The COVID-19 pandemic has forced governments to implement severe mobility restriction measures to limit the spread of the virus. This represented a unique opportunity to study the impact of mobility on urban air quality. Several studies which have investigated the relations between the quality of the air and such containment measures have shown the significant reduction of the main pollutants in the urban environment so to encourage the adoption of new approaches for the improvement of the quality of air in the cities. The aims of this entry are both a brief analysis and a discussion of the results presented in several papers to understand the relationships between COVID-19 containment measures and air quality in urban areas.

Keywords: Covid-19; lockdown; air pollution

\section{Introduction}

Air pollution is a mixture of particles and gases whose sources and composition vary spatially and temporally. Air pollution in the environment derives both from anthropogenic and natural sources. While natural sources contribute mainly to air pollution in not anthropized regions (e.g., forest fires and dust storms), the contributions from human activities from anthropized regions far exceed the ones from natural sources [1].

The major anthropogenic sources of air pollution are [1]:

- Combustion of fuel in vehicle engines

- Heat and power plants

- Industrial facilities

- Waste incineration facilities

- Residential activities such as cooking, heating, and lighting with energy produced with the use of polluting fuels

The uncontrolled expansion of urban areas owing to the need to favor the then-nascent automotive industry represents one of the major factors for the acceleration of pollutants emissions and diffusion.

Short- or long-term exposures to ambient air pollution represent high risks of both morbidity and mortality and contribute heavily to the global burden of disease. The most 
dangerous air pollutants are particulate matter $(\mathrm{PM})$, nitrogen dioxide $\left(\mathrm{NO}_{2}\right)$, ozone $\left(\mathrm{O}_{3}\right)$, and sulfur dioxide $\left(\mathrm{SO}_{2}\right)$.

The main problem with most ambient air-polluting emissions is that, even if they derive from localized point sources, their effects are not confined to limited areas. In fact, it has been demonstrated that pollutants can travel long distances in a matter of days under favorable meteorological conditions. Therefore, health and air quality in remote areas can be affected by windblown dust, which contains high levels of particles, bacteria, and fungal spores, from desert regions like Mongolia, Africa, China, and Central Asia. Since air pollutants cross national borders over time, it seems clear that it is necessary to address this problem by adopting both global and local control policies to reduce emissions.

It is estimated that about 7 million individuals die worldwide each year due to high air pollution exposure. Ambient air pollution exposure is one of the greatest risks to health worldwide. It is estimated to be responsible for about 4.2 million deaths around the world every year owing to many serious diseases such as heart disease, stroke, acute and chronic respiratory diseases, and lung cancer. From an economic point of view, the total welfare loss in 2013 amounts to more than US\$5 trillion in total welfare. According to the WHO, there is already ample evidence that children are more vulnerable to air pollution because they breathe more often, taking in more pollutants, and their nose and mouth are closer to the ground, which is where some pollutants are present in higher concentrations [2]. It is estimated that about $90 \%$ of the world's population is exposed to high air pollution levels, especially in low- and middle-income countries. [3]. WHO guideline values (Table 1) are set for the protection of health and are generally stricter than the comparable politically agreed-upon government standards [4]. WHO guidelines apply globally and are based on expert evaluation of current scientific evidence for the following pollutants: particulate matter $(\mathrm{PM})$, ozone $\left(\mathrm{O}_{3}\right)$, nitrogen dioxide $\left(\mathrm{NO}_{2}\right)$, sulfur dioxide $\left(\mathrm{SO}_{2}\right)$ [5]. Most sources of outdoor air pollution are well beyond the control of both individuals and local authorities and require concerted actions from national and regional level policy-makers working in sectors like transports, energy productions, waste management, urban planning, industry, and agriculture [6].

Table 1. WHO air quality guidelines.

\begin{tabular}{ccc}
\hline & \multicolumn{2}{c}{ Guideline Levels $\left(\mu \mathrm{g} / \mathrm{m}^{3}\right)$} \\
\hline \multirow{2}{*}{$\mathrm{PM}_{2.5}$} & 1 year & 10 \\
\cline { 2 - 3 } & $24 \mathrm{~h}(99$ th percentile $)$ & 25 \\
\cline { 2 - 3 } $\mathrm{PM}_{10}$ & 1 year & 20 \\
\hline \multirow{2}{*}{$\mathrm{NO}_{2}$} & $24 \mathrm{~h}(99$ th percentile $)$ & 50 \\
\cline { 2 - 3 } & 1 year & 40 \\
\hline $\mathrm{O}_{3}$ & $1 \mathrm{~h}$ & 200 \\
\hline \multirow{2}{*}{$\mathrm{SO}_{2}$} & $8 \mathrm{~h}$, daily maximum & 200 \\
\hline & $24 \mathrm{~h}$ & 500 \\
\hline
\end{tabular}

The set of mobility restrictive measures to limit the spread of COVID-19 imposed by the governments gave a unique opportunity to improve our understanding of the impact of mobility on air pollution in urban areas. Most governments have tried to contain the diffusion of COVID-19 through lockdowns, quarantines, and curfews, which have restricted people's movement, but for indispensable needs such as buying foods, work, and health-related issues. Moreover, all non-essential industries in most countries have been shut down, and people's movements were further restricted by imposing requirements for citizens to provide a signed justification to the authorities to be able to move both between and within cities. The effect of the lockdown on mobility was very relevant, 
and several studies have measured how lockdowns have modified mobility patterns at both country and local scales. For example, lockdown measures in France caused a 65\% reduction in a countrywide number of displacements and were particularly effective in reducing work-related short-range mobility, especially during rush hours, and long-range recreational trips [7]. Another study highlighted that the adoption of strong and severe measures for the containment of the spreading of COVID-19 during the period from March to April 2020 generated a significant reduction in private vehicle trips in the city of Rome ( $-64.6 \%$ during the lockdown) [8]. Community Mobility Reports, which were created with aggregated, anonymized sets of data from users who have turned on the Location History setting from their Google Account, provide useful information for the researchers who want to study the relationship between air pollutants levels and lockdown measures. These Community Mobility Reports aim at providing insights into what has changed in response to the policies aimed at contrasting COVID-19. The reports chart movement trends over time by geography across different categories of places such as retail and recreation, groceries and pharmacies, parks, transit stations, workplaces, and residential [9]. Several studies used human mobility data collected from Google (at country-scale) mobility reports to examine the status of improved air quality in world cities due to COVID-19 that led to a temporary reduction in anthropogenic emissions [10]. For example, the analysis of the changes in air quality during the COVID-19 lockdown in Singapore used human mobility trends from Google [11], as well as a study that found empirical evidence for a relation between global vehicle transportation declines and the reduction of ambient $\mathrm{NO}_{2}$ exposure [12].

This entry aims at obtaining a broad perspective on the impact of lockdown measures during the COVID-19 pandemic on the air quality in urban environments. For this purpose, we discussed the results reported by several studies in order to better understand the relationships between COVID-19 lockdown measures, the levels of the major pollutants in urban environments, and possibly identify which sectors contribute most to determining the levels of the pollutants. We included in this entry the following pollutants: $\mathrm{PM}_{2.5}, \mathrm{PM}_{10}$, $\mathrm{NO}_{2}, \mathrm{O}_{3}, \mathrm{SO}_{2}$.

\section{Association between Air Quality and Covid-19 Lockdown Measures}

\subsection{Particulate Matter}

With the term Particulate Matter (PM), we denote a mixture of liquid droplets and solid particles that can be found in the air. PM is not a pollutant by itself but a complex and dynamic combination of compound particles with biological and chemical origins. The main components of PM are primarily sulfites, ammonia, nitrates, sodium chloride, mineral dust, black carbon, and water. Particles with an aerodynamic diameter less than 10 microns $\left(\mathrm{PM}_{10}\right)$ and fine particles of less than 2.5 microns width $\left(\mathrm{PM}_{2.5}\right)$ represent the greatest risks for health owing to their capability of penetrating human lungs and so enter into their bloodstream. Ambient PM, especially $\mathrm{PM}_{2.5}$ [13], can also absorb poisonous pollutants, such as heavy metals, polycyclic aromatic hydrocarbons (PAHs), and VOCs. The main sources of PM include both diesel and petrol engines, the combustion of solid fuels such as coal, lignite, heavy oil, and biomass for the production of energy, as well as many other industrial activities such as building, mining, manufacture of cement, ceramic, and bricks, and smelting. Globally, $25 \%$ of urban ambient air pollution from $\mathrm{PM}_{2.5}$ derives from traffic, $15 \%$ from industrial activities, $20 \%$ from domestic fuel burning, $22 \%$ from unspecified sources of human origin, and 18\% from natural dust and salt [14]. Solutions for the sustainable reduction of ambient PM from traffic, industrial activities, and biomass burning should urgently be designed and implemented to reduce the air pollution in cities and the substantial disease burden it causes.

The comparative analysis of the $\mathrm{PM}_{10}$ and $\mathrm{PM}_{2.5}$ concentrations were carried out in several studies between normal mobility and lockdown periods. One of these studies [15] analyzed $\mathrm{PM}_{2.5}$ changes in the 50 most polluted capital cities in the world. The levels of air pollutants were collected from the air quality monitoring stations, which are provided by 
local environmental agencies. Overall, an average decrease of $12 \%$ of the $\mathrm{PM}_{2.5}$ levels was observed. The highest decrease was observed in the African continent, followed by the American (22\%) and the Asian (16\%). In the European cities, in which we have an overall better air quality in normal times, only a reduction of $5 \%$ has been observed. A similar study carried out a comparative analysis of the variation in the $\mathrm{PM}_{10}$ and $\mathrm{PM}_{2.5}$ levels of 12 cities from countries highly affected by COVID-19 [16]. The values of concentrations were collected from 162 air quality stations distributed in 12 selected cities. The concentration of $\mathrm{PM}_{2.5}$ and $\mathrm{PM}_{10}$ were reduced by $20 \%$ and $34 \%$, respectively, due to restrictions on anthropogenic emission sources during the lockdown. Other studies have focused on the study of the effects of Covid-19 lockdown measures on small-medium cities. For example, Donzelli et al. (2020) [17] studied the association between the mobility restrictions during the COVID-19 lockdown and the air pollutants levels recorded in three Italian cities, Florence, Pisa, and Lucca. For these aims, the authors also made use of meteorological data on rainfall, wind speed, temperature, relative humidity, and solar irradiance for the lockdown period and the same period of the preceding years. In fact, meteorological parameters have an important role in determining air pollution concentrations, so the authors decided to include these parameters in the analysis. Specifically for particulate matter, it is known that PM levels decrease with an increase in precipitation rate, wind speed, and temperature [18]. No evidence of a direct relationship was observed between the lockdown measures implemented by the Italian government and a reduction of PM in such cities, except in areas characterized by heavy vehicular traffic. This result is in line with the above-mentioned study, in which it was observed that the reductions in a European country of $\mathrm{PM}_{2.5}$ are much smaller than in more heavily polluted areas of the planet. Moreover, the study of Dantas et al. (2020) [19] reported an increase in the $\mathrm{PM}_{10}$ concentrations in two air quality monitoring stations of the city of Rio de Janeiro, Brazil.

\subsection{Nitrogen Dioxide}

The main sources of nitrogen dioxide from human activities are constituted by power generation, traffic, and industry. It represents a relevant precursor of both ozone and particulate matter. Respiratory infections, as well as reduced lung function and growth and symptoms of bronchitis and asthma, can increase in people who are exposed to this type of pollutant. In addition, it is well known that nitrogen dioxide exposure is linked with higher morbidity and mortality rates related to cardiovascular and respiratory diseases.

Several studies have proved a reduction of the nitrogen dioxide $\left(\mathrm{NO}_{2}\right)$ concentrations during the lockdown period when confronted with the years or months before the lockdown. In general, reductions of concentrations in $\mathrm{NO}_{2}$ are much more marked than those of PM, up to reaching reductions greater than $50 \%$ [20]. It is also possible to evaluate such reductions of concentrations using Tropospheric $\mathrm{NO}_{2}$ vertical column density (VCD) from the TROPOspheric Monitoring Instrument (TROPOMI) [21]. This instrument has been used by Bassani et al. (2021) [22] for the evaluation of changes in the concentrations of $\mathrm{NO}_{2}$ in Rome before and during the lockdown. The authors have observed reductions of $50 \%, 34 \%$, and $20 \%$ at urban traffic, urban background, and rural background stations, respectively. Similarly, Donzelli et al. (2021) [23], nitric oxide levels were significantly reduced in seven air monitoring stations placed in the city of Valencia, Spain. Considerable $\mathrm{NO}_{2}$ concentration variations between before and during the lockdown have been shown by several studies, like Mahato et al. (2020) [24], in which a reduction of 52.68\% is documented. These results are also consistent with those presented in the paper of Baldasano (2020) [25], in which it was observed a significant decrease in $\mathrm{NO}_{2}$ concentrations in Madrid and Barcelona of $62 \%$ and $50 \%$, respectively. Another article adopted a machine learning technique so as to analyze the effect of the COVID-19 lockdown measures on main air pollutant levels from January to April 2020 in six Chinese megacities with different lockdown durations. The authors have estimated that the lockdown measures reduced ambient $\mathrm{NO}_{2}$ concentrations by 36-53\% during the most restrictive periods [26]. The concentration of $\mathrm{NO}_{2}$ also showed a significant reduction of about $30 \%$ in the Gujarat 
state of western India, which has several cities characterized by poor air quality due to the presence of power plants, transportations, street dust, construction and brick kilns, and outdoor waste incineration, [27].

\subsection{Ozone}

Ground-level ozone $\left(\mathrm{O}_{3}\right)$, also known as tropospheric ozone, is among the most dangerous photochemical pollutants since people exposed to this type of pollutant are more at risk for the development of breathing problems, asthma, reduced lung function, and respiratory diseases. It falls in the class of secondary pollutants since it is not released directly into the atmosphere from the main sources of urban pollution, differently from what happens from primary pollutants. It is formed by the chemical reaction between carbon monoxide (CO), methane, or other volatile organic compounds (VOCs) and nitrogen oxides $\left(\mathrm{NO}_{\mathrm{x}}\right)$; this process occurs in the presence of sunlight. In addition to their role as ozone precursors, $\mathrm{CO}, \mathrm{VOCs}$, and $\mathrm{NO}_{\mathrm{x}}$ are by themselves dangerous air pollutants. The main sources of NOx and VOCs are traffic, industrial facilities, and chemical solvents. On the other hand, methane derives from waste, fossil fuels, and the agricultural industry. Aside from its health impacts, $\mathrm{O}_{3}$ is one of the most impacting greenhouse gases and one of the most significant short-lived climate pollutants.

Compared to the other pollutants, $\mathrm{O}_{3}$ concentrations show a different behavior since they exhibit a rise in terms of concentrations during the lockdown period. For example, one of the studies we took into consideration showed that the average daily concentrations of $\mathrm{O}_{3}$ are significantly increased in urban stations by $14 \%$ in Rome, $24 \%$ in Nice, $2.4 \%$ in Valencia, 27\% in Turin, and 36\% in Wuhan during the lockdown in 2020 [28]. This different behavior can be explained by an unprecedented reduction in $\mathrm{NO}_{\mathrm{x}}$ emissions, leading to a lower $\mathrm{O}_{3}$ titration by NO. The above-mentioned study showed that no significant reductions in ozone levels were observed during the lockdown period. These results are confirmed by further studies, like the study that investigated the effects on air quality in Milan [29], where a marked increase in $\mathrm{O}_{3}$ was reported. Moreover, Sharma et al. (2020) [30] and Tobías et al. (2020) [31] showed a rise of $17 \%$ and $57.7 \%$ in $\mathrm{O}_{3}$ concentrations in India and Barcelona, respectively. Another study aimed at evaluating the Covid-19 lockdown impact on air pollutants levels in the Mexico City Metropolitan Area [32]. This study showed an increase of $\mathrm{O}_{3}$ concentrations between $16 \%$ and $40 \%$ at the same sites where $\mathrm{NO}_{2}$ decreased, and it suggested that in order to reduce the concentrations of $\mathrm{O}_{3}$, the to be adopted policies should focus on the reduction of the emissions of VOCs from fixed sources. Moreover, Patel et al. (2020) showed that while all other pollutants showed a marked reduction in concentrations during the lockdown, $\mathrm{O}_{3}$ recorded a statistically significant $(\mathrm{t}=-3.59, p<0.05)$ increase in daily mean concentrations $\left(5.52 \mu \mathrm{g} / \mathrm{m}^{-3}(+16.7 \%)\right)$ in Auckland, New Zealand, an isolated city of the Southern Hemisphere which is largely unaffected by long-range pollution transports or industrial sources of air pollution [33].

\subsection{Sulfur Dioxide}

The main sources of sulfur dioxide $\left(\mathrm{SO}_{2}\right)$ are constituted by the burning of fossil fuels (e.g., oil and coal) and the smelting of mineral ores that contain sulfur. People exposed to $\mathrm{SO}_{2}$ are more at risk of developing damages to the respiratory system and the functionality of the lungs, as well as eye irritation. It is known that some pre-existing diseases, such as chronic bronchitis and asthma, can be aggravated in exposed people. Moreover, it is shown an increased risk of infections responsible for raised visits to emergency rooms and hospital admissions. If $\mathrm{SO}_{2}$ reacts with water molecules in the atmosphere, it forms sulfuric acid, which is the main component of acid rain and one of the main causes of damage to the forests, freshwaters, and soils.

Changes in $\mathrm{SO}_{2}$ concentrations were studied by several researchers. For example, Otmani et al. (2020) [34] assessed the variation of $\mathrm{SO}_{2}$ concentrations in the ambient air of Salé city before and during the few days into the implementation of the lockdown measures. The authors reported a reduction of $49 \%$ of $\mathrm{SO}_{2}$ levels, even though the low 
$\mathrm{SO}_{2}$ concentrations recorded in the full study period do not allow for evidencing a definite trend. An analysis produced using data from the Tropomi instrument on the Copernicus Sentinel-5P satellite showed that concentrations of $\mathrm{SO}_{2}$ in polluted areas in India have decreased by about 40\% between April 2019 and April 2020 [35]. These results were also confirmed by a study investigating how levels of $\mathrm{SO}_{2}$ in four Tunisian cities varied during the months from January to April 2020. The authors reported reductions in all the cities up to $52 \%$ [36].

\section{Conclusions}

Based on the analyzed papers, we can state that there is evidence from various data and studies that there has been a reduction in air pollution all over the world. Although most of the studies reported significant reductions in the levels of some pollutants, we believe that these results should be interpreted with caution due to the lack of some data in the analysis. It is likely that some studies have overestimated the reductions, for example, not considering the long-term trends as potential confounding [37]. In fact, the comparisons between the pollution levels of the pandemic year with the previous years are intrinsically subject to distortions due to the simple fact that each year is characterized by different conditions, for example, economic conditions, that have not been duly assessed. With regard to meteorological conditions, the majority of studies took into consideration the atmospheric parameters to reduce the bias in the data analyses. We must also point out that different methodologies were used in the different studies, so that it is hard to compare the different results. For example, regarding the period of times which were compared, we noticed that some studies compared the air pollutants concentrations before and during the lockdown, while other compared the previous year (2019) with the first pandemic year (2020) and still others the mean concentrations of the previous five years (2015-2019). Furthermore, there were differences among the containment measures adopted by different governments, so that it is not easy to compare the reductions of the air pollutants under study directly. Finally, various analytic techniques were used by different authors, which used both classical approaches like statistical tests and more advanced methods like machine learning.

However, we can conclude that the implementation of the lockdown measures reduced the levels of $\mathrm{PM}_{10}$ and $\mathrm{PM}_{2.5}$ in most areas under study. Notwithstanding this, we should consider that this difference is more important in most pollutant areas of the planet, while smaller effects were observed in the European countries in which the air quality is generally better. We must remember that some studies did not observe a decrease in PM levels, and others did not detect a significant difference with the periods of normality mobility. Regarding $\mathrm{NO}_{2}$, the reductions appear more marked and more homogeneously distributed in the various areas of the globe than those of PM. Most of the studies reported changes in concentrations not smaller than $50 \%$. However, reductions in $\mathrm{NO}_{2}$ concentration cannot be conclusively calculated without adjusting for long-term trends, which may partially contribute to confounding bias [38]. In fact, it was observed that trends in $\mathrm{NO}_{2}$ concentrations have gradually decreased in the last decade due to the change in industrial and vehicular emissions obtained thanks to technological and economic development and emission regulations [39]. Moreover, $\mathrm{SO}_{2}$ concentrations decreased during the lockdown period, though with more modest changes. Conversely, concentrations of $\mathrm{O}_{3}$ increased in different cities due to the significant lowering of the NO concentration in the lockdown period, which, in turn, reacts with $\mathrm{O}_{3}$ to cause higher $\mathrm{O}_{3}$ concentrations than average. This suggests the need for a holistic approach when we have to implement policies to improve the air quality and protect both human health and the environment.

Author Contributions: Conceptualization, M.M.-S.-V. and G.D.; writing—original draft preparation, G.D., L.C., M.C. and A.L.-M.; writing—review and editing, M.M.-S.-V. and G.D.; supervision, M.M.S.-V. All authors have read and agreed to the published version of the manuscript.

Funding: This research received no external funding. 
Acknowledgments: We wish to thank Maria Grazia De Agazio for proofreading, editing, and assisting with translating the manuscript into English.

Conflicts of Interest: The authors declare no conflict of interest.

Entry Link on the Encyclopedia Platform: https:/ / encyclopedia.pub/12559.

\section{References}

1. WHO. Ambient Air Pollution: Pollutants. Available online: https://www.who.int/airpollution/ambient/pollutants/en/ (accessed on 10 October 2020).

2. WHO. WHOI Air Pollution and Child Health: Prescribing Clean Air. Available online: http://www.who.int/ceh/publications/ air-pollution-child-health/en/ (accessed on 29 April 2021).

3. WHO. WHOIAmbient Air Pollution. Available online: http://www.who.int/airpollution/ambient/en/ (accessed on 29 April 2021).

4. European Environment Agency Air Quality Standards. Available online: https://www.eea.europa.eu/themes/air/air-qualityconcentrations / air-quality-standards (accessed on 28 October 2020).

5. WHO. WHO I Air Quality Guidelines-Global Update 2005. Available online: http://www.who.int/airpollution/publications / aqg2005/en/ (accessed on 29 April 2021).

6. WHO Health Organization. Ambient (Outdoor) Air Pollution. Available online: https://www.who.int/news-room/fact-sheets/ detail/ambient-(outdoor)-air-quality-and-health (accessed on 3 March 2020).

7. Pullano, G.; Valdano, E.; Scarpa, N.; Rubrichi, S.; Colizza, E.V. Population mobility reductions during COVID-19 epidemic in France under lockdown. medRxiv 2020. [CrossRef]

8. Aletta, F.; Brinchi, S.; Carrese, S.; Gemma, A.; Guattari, C.; Mannini, L.; Patella, S.M. Analysing urban traffic volumes and mapping noise emissions in Rome (Italy) in the context of containment measures for the COVID-19 disease. Noise Mapp. 2020, 7 , 114-122. [CrossRef]

9. COVID-19 Community Mobility Report. Available online: https://www.google.com/covid19/mobility?hl=en (accessed on 29 April 2021).

10. Sannigrahi, S.; Kumar, P.; Molter, A.; Zhang, Q.; Basu, B.; Basu, A.S.; Pilla, F. Examining the status of improved air quality in world cities due to COVID-19 led temporary reduction in anthropogenic emissions. Environ. Res. 2021, 196, 110927. [CrossRef] [PubMed]

11. Li, J.; Tartarini, F. Changes in Air Quality during the COVID-19 Lockdown in Singapore and associations with Human Mobility Trends. Aerosol Air Qual. Res. 2020, 20, 1748-1758. [CrossRef]

12. Venter, Z.S.; Aunan, K.; Chowdhury, S.; Lelieveld, J. COVID-19 lockdowns cause global air pollution declines. Proc. Natl. Acad. Sci. USA 2020, 117, 18984-18990. [CrossRef] [PubMed]

13. Ramli, N.A.; Yusof, N.F.F.M.; Shith, S.; Suroto, A. Chemical and Biological Compositions Associated with Ambient Respirable Particulate Matter: A Review. Water Air Soil Pollut. 2020, 231, 1-14. [CrossRef]

14. Karagulian, F.; Belis, C.A.; Dora, C.F.C.; Prüss-Ustün, A.M.; Bonjour, S.; Adair-Rohani, H.; Amann, M. Contributions to cities' ambient particulate matter (PM): A systematic review of local source contributions at global level. Atmos. Environ. 2015, 120, 475-483. [CrossRef]

15. Rodríguez-Urrego, D.; Rodríguez-Urrego, L. Air quality during the COVID-19: PM2.5 analysis in the 50 most polluted capital cities in the world. Environ. Pollut. 2020, 266, 115042. [CrossRef]

16. Kumari, P.; Toshniwal, D. Impact of lockdown on air quality over major cities across the globe during COVID-19 pandemic. Urban Clim. 2020, 34, 100719. [CrossRef]

17. Donzelli, G.; Cioni, L.; Cancellieri, M.; Morales, A.L.; Suárez-Varela, M.M. The Effect of the Covid-19 Lockdown on Air Quality in Three Italian Medium-Sized Cities. Atmosphere 2020, 11, 1118. [CrossRef]

18. Galindo, N.; Varea, M.; Gil-Moltó, J.; Yubero, E.; Nicolás, J. The Influence of Meteorology on Particulate Matter Concentrations at an Urban Mediterranean Location. Water Air Soil Pollut. 2010, 215, 365-372. [CrossRef]

19. Dantas, G.; Siciliano, B.; França, B.B.; da Silva, C.M.; Arbilla, G. The impact of COVID-19 partial lockdown on the air quality of the city of Rio de Janeiro, Brazil. Sci. Total. Environ. 2020, 729, 139085. [CrossRef] [PubMed]

20. Nakada, L.Y.K.; Urban, R.C. COVID-19 pandemic: Impacts on the air quality during the partial lockdown in São Paulo state, Brazil. Sci. Total. Environ. 2020, 730, 139087. [CrossRef] [PubMed]

21. Home I Tropomi. Available online: http://www.tropomi.eu/ (accessed on 29 April 2021).

22. Bassani, C.; Vichi, F.; Esposito, G.; Montagnoli, M.; Giusto, M.; Ianniello, A. Nitrogen dioxide reductions from satellite and surface observations during COVID-19 mitigation in Rome (Italy). Environ. Sci. Pollut. Res. 2021, 28, 22981-23004. [CrossRef]

23. Donzelli, G.; Cioni, L.; Cancellieri, M.; Llopis-Morales, A.; Morales-Suárez-Varela, M. Relations between Air Quality and Covid-19 Lockdown Measures in Valencia, Spain. Int. J. Environ. Res. Public Health 2021, 18, 2296. [CrossRef]

24. Mahato, S.; Pal, S.; Ghosh, K.G. Effect of lockdown amid COVID-19 pandemic on air quality of the megacity Delhi, India. Sci. Total. Environ. 2020, 730, 139086. [CrossRef] [PubMed]

25. Baldasano, J.M. COVID-19 lockdown effects on air quality by $\mathrm{NO}_{2}$ in the cities of Barcelona and Madrid (Spain). Sci. Total. Environ. 2020, 741, 140353. [CrossRef] [PubMed] 
26. Wang, Y.; Wen, Y.; Wang, Y.; Zhang, S.; Zhang, K.M.; Zheng, H.; Xing, J.; Wu, Y.; Hao, J. Four-Month Changes in Air Quality during and after the COVID-19 Lockdown in Six Megacities in China. Environ. Sci. Technol. Lett. 2020, 7, 802-808. [CrossRef]

27. Selvam, S.; Muthukumar, P.; Venkatramanan, S.; Roy, P.; Bharath, K.M.; Jesuraja, K. SARS-CoV-2 pandemic lockdown: Effects on air quality in the industrialized Gujarat state of India. Sci. Total. Environ. 2020, 737, 140391. [CrossRef]

28. Sicard, P.; De Marco, A.; Agathokleous, E.; Feng, Z.; Xu, X.; Paoletti, E.; Rodriguez, J.J.D.; Calatayud, V. Amplified ozone pollution in cities during the COVID-19 lockdown. Sci. Total. Environ. 2020, 735, 139542. [CrossRef] [PubMed]

29. Collivignarelli, M.C.; Abbà, A.; Bertanza, G.; Pedrazzani, R.; Ricciardi, P.; Miino, M.C. Lockdown for CoViD-2019 in Milan: What are the effects on air quality? Sci. Total. Environ. 2020, 732, 139280. [CrossRef]

30. Sharma, S.; Zhang, M.; Gao, J.; Zhang, H.; Kota, S.H. Effect of restricted emissions during COVID-19 on air quality in India. Sci. Total. Environ. 2020, 728, 138878. [CrossRef] [PubMed]

31. Tobías, A.; Carnerero, C.; Reche, C.; Massagué, J.; Via, M.; Minguillón, M.C.; Alastuey, A.; Querol, X. Changes in air quality during the lockdown in Barcelona (Spain) one month into the SARS-CoV-2 epidemic. Sci. Total. Environ. 2020, 726, 138540. [CrossRef] [PubMed]

32. Hernández-Paniagua, I.Y.; Valdez, S.I.; Almanza, V.; Rivera-Cárdenas, C.; Grutter, M.; Stremme, W.; García-Reynoso, A.; RuizSuárez, L.G. Impact of the COVID-19 Lockdown on Air Quality and Resulting Public Health Benefits in the Mexico City Metropolitan Area. Front. Public Health 2021, 9, 642630. [CrossRef] [PubMed]

33. Patel, H.; Talbot, N.; Salmond, J.; Dirks, K.; Xie, S.; Davy, P. Implications for air quality management of changes in air quality during lockdown in Auckland (New Zealand) in response to the 2020 SARS-CoV-2 epidemic. Sci. Total. Environ. 2020, 746, 141129. [CrossRef] [PubMed]

34. Otmani, A.; Benchrif, A.; Tahri, M.; Bounakhla, M.; Chakir, E.M.; El Bouch, M.; Krombi, M. Impact of Covid-19 lockdown on PM10, SO2 and NO2 concentrations in Salé City (Morocco). Sci. Total. Environ. 2020, 735, 139541. [CrossRef]

35. Sulphur Dioxide Concentrations Drop over India during COVID-19. Available online: https://www.esa.int/Applications/ Observing_the_Earth/Copernicus/Sentinel-5P/Sulphur_dioxide_concentrations_drop_over_India_during_COVID-19 (accessed on 29 April 2021).

36. Chekir, N.; Ben Salem, Y. What is the relationship between the coronavirus crisis and air pollution in Tunisia? Euro-Mediterr. J. Environ. Integr. 2021, 6, 1-9. [CrossRef] [PubMed]

37. Shi, Z.; Song, C.; Liu, B.; Lu, G.; Xu, J.; Van Vu, T.; Elliott, R.J.R.; Li, W.; Bloss, W.J.; Harrison, R.M. Abrupt but smaller than expected changes in surface air quality attributable to COVID-19 lockdowns. Sci. Adv. 2021, 7, eabd6696. [CrossRef]

38. Misra, P.; Takigawa, M.; Khatri, P.; Dhaka, S.K.; Dimri, A.P.; Yamaji, K.; Kajino, M.; Takeuchi, W.; Imasu, R.; Nitta, K.; et al. Nitrogen oxides concentration and emission change detection during COVID-19 restrictions in North India. Sci. Rep. 2021, 11, 1-11. [CrossRef]

39. Lamsal, L.N.; Duncan, B.N.; Yoshida, Y.; Krotkov, N.A.; Pickering, K.E.; Streets, D.G.; Lu, Z.U.S. NO 2 trends (2005-2013): EPA Air Quality System (AQS) data versus improved observations from the Ozone Monitoring Instrument (OMI). Atmos. Environ. 2015, 110, 130-143. [CrossRef] 